\title{
O Agir Crítico em Nutrição na Atenção Primária à Saúde e suas Potencialidades à Luz da Concepção da Educação Popular
}

\author{
Critical Action in Nutrition in Primary Health Care and its \\ Potentialities in Light of the Conception of Popular Education
}

\author{
Pedro José Santos Carneiro Cruz \\ 'Universidade Federal da Paraíba (UFPB), Centro de Ciências Médicas, Departamento de Promoção da Saúde, \\ João Pessoa, PB, Brasil. \\ E-mail: pjcruzpb@gmail.com
}

Resumo: Este trabalho busca evidenciar potencialidades do agir crítico em nutrição na Atenção Primária à Saúde diante de uma experiência de promoção da Segurança Alimentar e Nutricional em ações comunitárias e de práticas de Educação Alimentar e Nutricional orientadas pela concepção da Educação Popular. O estudo considerou percepções de participantes da referida experiência. Formularam-se sínteses sobre o agir crítico em nutrição: (1) requer engajamento e compromisso com a realidade social; (2) é construído de forma compartilhada e participativa; (3) sua construção ocorre em meio ao conflito e ao enfrentamento do capitalismo; e (4) reorienta o fazer tradicional e reposiciona o trabalho em nutrição na perspectiva da segurança alimentar e nutricional. Por meio da educação popular, o trabalho na atenção primária à saúde pode construir práticas de educação alimentar e nutricional orientadas pelo diálogo acerca das estratégias para posicionar alimentação e nutrição de maneira coerente com a compreensão da saúde como qualidade de vida e bem viver.

Palavras-chave: Educação alimentar; Programa de saúde; Nutrição em saúde pública. Educação popular.

Abstract: This work seeks to highlight the potential of critical action in nutrition in Primary Health Care in the face of an experience of promoting Food and Nutrition Security in community actions, and in Food and Nutrition Education practices guided by the conception of Popular Education. The study considered participants' perceptions about the experience. Overviews of critical action in nutrition were formulated: (1) it requires engagement and commitment to social reality; (2) it is built in a shared and participative way; (3) its construction takes place amid the conflict and the confrontation of capitalism; and (4) it redirects the traditional approach and repositions nutrition work from the perspective of food and nutrition security. Through popular education, work in primary health care can build food and nutrition education practices guided by dialogue about strategies to position food and nutrition in a manner that is consistent with the understanding of health as quality of life and well-being.

Keywords: Food education; Health care program; Public health nutrition; Popular education.

Recebido em: 09/06/2019

Aprovado em: 07/02/2020 


\section{Introdução}

O debate em torno de um agir crítico em nutrição constitui destaque no âmbito da produção científica e das reflexões acadêmicas e profissionais em saúde desde muitas décadas. No entanto, pode-se apontar especificamente os anos de 1970 como marco, onde um amplo movimento de reorientação do fazer e do pensar a ciência da Nutrição e sua prática profissional passou a ganhar ênfase. Nas últimas duas décadas, esse movimento foi especialmente impulsionado por diversos fatores de interesse social e científico, dentre os quais se destacam: a persistência do fenômeno da exclusão social no mundo, que patrocina a fome, a pobreza e a miséria (RIBEIRO, 2010); as recentes mudanças políticas, econômicas, sociais e culturais, que resultam diretamente em transformações nos modos de vida da população e, consequentemente, em suas relações com a comida e o comer (JACOB; CHAVES, 2019); e o crescente interesse pela interface entre alimentação e cultura, seja em uma perspectiva antropológica, seja para compreender, na cotidianidade da vida humana, os impasses com que os indivíduos se deparam frente às suas escolhas alimentares (CONTRERAS; GRACIA, 2011).

Há de se destacar ainda a ampliação das políticas públicas em campos como saúde, educação, trabalho e assistência social, em ações voltadas para o enfrentamento das desigualdades sociais (SÁTYRO et al., 2019). No Brasil, tal processo permitiu que o país crescesse de forma inclusiva e protagonizasse uma significativa transição demográfica, epidemiológica e nutricional, caracterizada por "[...] maior expectativa de vida [...], além de mudanças importantes no padrão de saúde e consumo alimentar da população" (BRASIL, 2014, p. 5).

Conforme destacado no Guia alimentar para a população brasileira (BRASIL, 2014), para atuar nesse cenário, é primordial o desenvolvimento de uma ação profissional em nutrição que consiga repercutir positivamente sobre os diversos determinantes da saúde e nutrição e que atue na promoção da alimentação adequada e saudável. Tal necessidade é reforçada pelo contexto social e político de crise instalado no país a partir do ano de 2016, quando, após um processo de ruptura governamental pela deposição da presidenta eleita Dilma Rousseff, vários retrocessos nas políticas públicas da área passaram a decorrer, quer pela redução de investimentos, pela extinção de unidades institucionais, ou por mudanças na legislação que colocam em risco direitos sociais e humanos essenciais, conforme aponta Fleury (2018).

Marques (2013) diz que, nesse contexto, configura-se um ideário de "sacralização do mercado" que justifica e fundamenta transformações no âmbito de sistemas econômicos, políticos e sociais. Por um lado, encaminhando a reestruturação do modelo capitalista, por outro, impactando em consequências sensíveis para as relações de trabalho e no trabalho. Dentre os efeitos dessas políticas de austeridade, destacam-se processos sensíveis como falências, desemprego (atingindo em especial a juventude), redução de salários, precarização das condições de trabalho, aumento no endividamento público e privado, crescente desmonte das condições de prestação dos serviços públicos, aumento nos níveis de desigualdade social, dificuldades econômicas e sofrimento social nos setores que já eram marginalizados. A operacionalização das políticas de proteção social - como a saúde, a alimentação e a nutrição - foi, portanto, progressivamente, perdendo seus fundamentos de apoio social em meio a reestruturações do capitalismo em suas crises (FLEURY, 2018). 
Diante desse contexto complexo, a ação profissional em nutrição deve se fundamentar em dimensões como o incentivo, apoio e proteção da saúde, além de combinar iniciativas focadas em políticas públicas saudáveis, como reorientação dos serviços de saúde, criação de ambientes saudáveis e desenvolvimento de habilidades pessoais em prol da promoção da saúde. Assim, visando, também, ao desenvolvimento de estratégias para a efetivação do Direito Humano à Alimentação Adequada e Saudável (DHAAS) e para o desvelamento de processos de Segurança Alimentar e Nutricional (SAN) (BRASIL, 2014). Nas palavras de Guerra, Cervato-Mancuso e Bezerra (2019), as concepções de DHAAS e de SAN implicam compreender a alimentação como

[...] direito de todo ser humano, do ponto de vista da saúde, do respeito à cultura alimentar, [...] da disponibilidade e do acesso permanente aos alimentos de qualidade, sem comprometer outras necessidades inerentes a uma vida digna, como a educação, moradia, emprego e lazer. (GUERRA; CERVATO-MANCUSO; BEZERRA, 2019, p. 3370).

A emergência dessas concepções nas políticas públicas brasileiras tem contribuído com um debate acerca da prática profissional em nutrição e das ações em Educação Alimentar e Nutricional (EAN), aproximando-as de perspectivas pedagógicas como a Educação Popular (EP), centralmente a partir dos fundamentos assentados na obra de Paulo Freire. Para Acioli et al. (2002), a EP constitui um processo de construção compartilhada do conhecimento, que se desenvolve pela interação em que sujeitos possuidores de saberes diferentes se articulam a partir de interesses comuns. Esse tipo de prática envolve aspectos de natureza pedagógica e metodológica, com uma proposta que estimula a participação das pessoas envolvidas e abre o seu universo de respostas, passando pelas condições de trabalho e vida da comunidade. É um processo formativo que, por meio de uma construção compartilhada de conhecimentos, visa o fomento da participação das pessoas. Brutscher $(2012$, p. 407) afirma que "[...] participação é estar junto, é envolvimento e responsabilização". E, ainda, que "[...] direito não é um dado absoluto e definitivo, mas uma construção sócio-histórica; [...] participação requer ação, proposição e controle do estado e da sociedade como um todo" (BRUTSCHER, 2012, p. 409).

Entretanto, na literatura da área, persistem importantes lacunas quanto à reflexão sobre a dimensão do trabalho e da ação profissional em nutrição com o olhar da educação popular (EP). Embora existam significativas iniciativas sociais e educacionais dedicadas a esse processo de reorientação do fazer profissional em nutrição, a literatura ainda precisa avançar no que se refere à explicitação dessas experiências e à apresentação de novas possibilidades metodológicas, éticas e políticas forjadas nessas ações. Conforme indicam Castro, Castro e Gugelmin (2011) e Santos (2012), ainda existe alguma distância entre o que é dito na teoria e o que é feito na prática cotidiana da Nutrição e do agir profissional nesse campo com uma perspectiva pedagógica participativa, dialógica e crítica. Ao estudarem as pesquisas sobre SAN no Brasil, de 2000 a 2005, Prado et al. (2010) evidenciaram a predominância de estudos sobre a qualidade dos alimentos (área de ciência e tecnologia dos alimentos) e o estado nutricional de grupos populacionais (área da nutrição), com pouco destaque, portanto, para estudos sobre a dimensão educativa da SAN e suas implicações em trabalhos sociais concretos nos territórios. 
Cruz e Melo Neto (2014) afirmam que, apesar de que muitos autores e obras tenham avançado quanto ao delineamento de possibilidades educativas que concretizem as intenções expressas nos conceitos de SAN e no marco do DHAAS, é necessário dedicar mais estudos e reflexões críticas na perspectiva de criar processos emancipatórios nas iniciativas de Educação Alimentar e Nutricional (EAN). Isso deverá colaborar não apenas com novos horizontes para a ação do nutricionista ou melhora do estado de SAN nas comunidades, mas também na reorientação do agir em nutrição. Para os autores, o debate teórico em torno do agir profissional em nutrição precisa refletir intensamente sobre seu compromisso social e seu significado no enfrentamento obstinado e cotidiano das condições objetivas de opressão, injustiça e desumanização, às quais está exposta parte significativa da população brasileira (CRUZ; MELO NETO, 2014).

Dentre os vários setores de atuação em nutrição, priorizou-se, no presente estudo, o campo da nutrição na Atenção Primária à Saúde (APS). Isso se justifica ao se considerar que o mesmo se encontra em franca expansão no que diz respeito à sua capacidade de evidenciar um leque de produções, reflexões e práticas, desvelando novos caminhos e conhecimentos para atuação crítica e integral em Nutrição, em consonância com as mudanças sociais, políticas, epidemiológicas, culturais e econômicas supracitadas (JAIME et al., 2018).

Para Giovanella e Mendonça (2008, p. 575), atenção primária refere-se ao "[...] conjunto de práticas em saúde, individuais e coletivas; [...] a base para um novo modelo assistencial de sistemas de saúde que tenham em seu centro o usuário-cidadão". De acordo com essas autoras, a Política Nacional de Atenção Básica (PNAB) tem incluído um conjunto de ações de promoção, prevenção, recuperação e reabilitação de saúde, através de serviços e estratégias, cujo fundamento está em constituir o contato preferencial e a porta de entrada do sistema de saúde para o usuário, com integralidade da atenção, priorizando a longitudinalidade e a coordenação dos cuidados. Tal concepção inclui, de modo destacado, a dimensão social e educacional do agir do profissional de saúde, de modo a promover elementos da APS, como a centralidade na família e o direcionamento para a comunidade.

Desse modo, a atuação na APS vem demandando dos profissionais da Nutrição um aprimoramento de seu protagonismo na construção de ações educativas e sociais, por meio de projetos e programas. Para tanto, perfazendo caminhos capazes de promover saúde com ênfase em estratégias coerentes com as realidades e problemáticas regionais relacionadas à fome e à miséria, envolvendo a SAN como mais um referencial singular no processo de desenvolvimento social e de combate à fome (BOOG, 2010; JAIME et al., 2011; SANTOS, 2005).

O objetivo central deste trabalho é contribuir com esse debate, evidenciando, particularmente, percepções de sujeitos acerca de potencialidades de um agir crítico em nutrição na APS, diante de uma experiência de promoção da SAN em ações comunitárias e de práticas de EAN orientadas pela perspectiva pedagógica freiriana da EP. Com isso, pretendeu-se mobilizar algumas reflexões comprometidas com a expansão e qualificação do debate sobre os atuais desafios, as possibilidades e as lacunas da nutrição em seu agir profissional na APS. 


\section{Metodologia}

Este estudo resultou de uma pesquisa de tese de doutoramento em Educação, construída na perspectiva qualitativa (MINAYO, 2008), a partir de abordagem de análise com perspectiva dialética (MELO NETO, 2002). Originou-se a partir de inquietações e de questões dirigidas ao grupo do qual o autor faz parte, em decorrência de sua experiência como participante de trabalhos sociais em Nutrição à luz da EP, particularmente do Programa de Extensão Práticas Integrais de Promoção da Saúde e Nutrição na Atenção Básica (PINAB) vinculado ao Departamento de Nutrição e ao Departamento de Promoção da Saúde da Universidade Federal da Paraíba (UFPB). Esse Programa está em exercício há treze anos, entrelaçando ações, grupos e processos educativos em alimentação, nutrição e saúde no contexto de comunidades populares, tendo como sujeitos, além de estudantes e docentes da UFPB, moradores, educadores populares, educadores de ensino fundamental e trabalhadores de uma Unidade de Saúde da Família (USF). No período estudado, o PINAB desenvolveu suas ações a partir do apoio a distintas práticas sociais de EP e Promoção da Saúde realizadas no território, a partir de Grupos Operativos, sendo estes: Brincando com a mente; HiperDia; Caminhada; Terapia Comunitária; e Horta no Vila. Há de se destacar também as ações do PINAB em apoio ao Movimento Popular de Saúde da Paraíba (MOPS-PB) e à Articulação Nacional de Movimentos e Práticas de Educação Popular em Saúde da Paraíba (ANEPS-PB) e um Fórum Intersetorial de Promoção da SAN.

Para promover uma reflexão aprofundada acerca da experiência foram consideradas percepções de sujeitos participantes desse processo, por meio da metodologia de grupos de discussão. Para Mangold (1960 apud WELLER, 2006, p. 245), nessa metodologia, "[...] a opinião do grupo não é a soma de opiniões individuais [...]. A participação de cada membro dá-se de forma distinta, mas as falas individuais são produto da interação mútua". Assim, nos grupos de discussão, podem-se explicar as visões de mundo dos sujeitos da pesquisa, que resultam, segundo Mannheim (1952 apud WELLER et al., 2002, p. 378-379), de "[...] uma série de vivências ou de experiências ligadas a uma mesma estrutura que, por sua vez, constituise como uma base comum das experiências que perpassam a vida de múltiplos indivíduos".

Houve duas sessões de grupos de discussão. A primeira, com duas horas de duração. O foco principal envolveu a reconstituição histórica da experiência estudada e a apreensão de seus elementos teóricos e práticos no que tange ao agir crítico em nutrição. Participaram desse grupo de discussão sete membros: um ex-estudante da turma fundadora do Programa em 2007 (que continua atuando voluntariamente como docente colaborador); dois exestudantes da segunda turma do PINAB, que ingressaram em 2009 e que, mesmo depois de formados em 2012, continuaram atuando voluntariamente como docentes colaboradores; um ex-estudante que veio de outra ação de Extensão Popular, que atua no PINAB há seis meses como colaborador; dois estudantes atuantes no PINAB na época da entrevista, que ingressaram em 2012; e um estudante de outra ação de Extensão Popular, com quatro anos de experiência em EP, que interage com o PINAB por meio do Núcleo de Educação Popular em Saúde da UFPB, o qual articula diferentes experiências nessa linha no âmbito dessa universidade. Nessa primeira discussão em grupo, o roteiro teve três questões geradoras fundamentais: (a) a reconstituição da história do PINAB; (b) os elementos que emergiram do PINAB, à luz da EP, no sentido de anunciar um agir crítico em nutrição na APS; e, (c) as contradições presentes no processo. 
O segundo grupo de discussão foi realizado com uma hora e meia de duração e dele participaram os mesmos sujeitos da sessão anterior. Seu foco principal foi agregar sentidos e concepções dos sujeitos acerca dos elementos teóricos e práticos da EP, que fundamentam um agir crítico em nutrição na APS. Os membros foram os mesmos do primeiro grupo. $O$ roteiro foi composto das seguintes perguntas: (a) em sua visão, o que é nutrição?; (b) em sua percepção, seria possível pensar em um agir crítico em nutrição na APS?; (c) em caso positivo, que elementos teóricos e práticos da EP fundamentariam esse agir? De que maneira? Recorreu-se também à utilização de depoimentos escritos dos mesmos - tanto publicados em um livro sobre a experiência estudada como registrados em relatórios institucionais. Tal iniciativa teve como intenção aprofundar a compreensão das ideias e das posições dos sujeitos da pesquisa, e somente foram operadas mediante autorização dos mesmos.

Os depoimentos dos grupos de discussão foram registrados por meio de filmagem em câmera digital e de gravador de voz via aparelho celular (smartphone). Ressalta-se que os registros da discussão em grupo foram assistidos e transcritos. Assim, foram adotadas as seguintes etapas: (1) assistir aos vídeos (duas vezes); (2) transcrever todas as falas; (3) ler e reler essas transcrições; (4) identificar as categorias emergentes nas falas no que tange à reconstituição histórica do PINAB e aos elementos teóricos e práticos do agir em nutrição à luz da EP; (5) agregar as categorias por proximidade de ideias e questões teóricas e inserilas no decorrer do texto, de forma coerente e coesa; (6) construir o diálogo das categorias com os demais dados de outras fontes documentais e bibliográficas e com as impressões do pesquisador, com base em sua experiência, conforme registros da observação participante.

Os dados apreendidos dos grupos de discussão, que serviram para reconstituir a história da experiência e fazer emergirem as categorias teóricas e práticas, bem como aprofundar a análise crítica do objeto de estudo, subsidiaram elementos para que se organizasse a pesquisa e elaborasse o texto, ao longo do qual os depoimentos resultantes das entrevistas são apresentados. A participação dos sujeitos da pesquisa foi assegurada com privacidade e preservação de sua identidade. Antes de proceder à coleta das informações cedidas pelos sujeitos do estudo, explicou-se quais eram os objetivos do estudo, expondo os instrumentos e entregando-Ihes a cópia do Termo de Consentimento Livre e Esclarecido (TCLE), que foi lido e, de acordo com sua posição, assinado. Esta pesquisa está em consonância com os preceitos que regem a Portaria n 466/2012 (BRASIL, 2012) e foi aprovada pelo Comitê de Ética e Pesquisa do Centro de Ciências da Saúde da UFPB, com CAAE no 42989515.0.0000.5188.

\section{Resultados e Discussão}

No processo de aproximação de análise das ideias emergentes da percepção dos entrevistados, foram necessárias três rodadas de formulação de categorias-síntese que explicitassem clara e fielmente potencialidades do agir crítico em nutrição na Atenção Primária à Saúde (APS) à luz da Educação Popular (EP). Diante disso, emergiram quatro formulações, as quais constituem eixos-síntese fundamentais para o alcance dos objetivos do estudo. 
Quadro 1 - Categorias emergentes das percepções dos sujeitos

\begin{tabular}{|c|c|c|}
\hline Primeira rodada & Segunda rodada & Terceira rodada \\
\hline $\begin{array}{l}\text { Engajamento com a realidade social circun- } \\
\text { dante }\end{array}$ & $\begin{array}{l}\text { O agir crítico em nutrição na APS requer o } \\
\text { engajamento e o compromisso com a rea- } \\
\text { lidade social }\end{array}$ & $\begin{array}{l}\text { O agir crítico em nutrição na APS requer } \\
\text { o engajamento e o compromisso com a } \\
\text { realidade social }\end{array}$ \\
\hline $\begin{array}{l}\text { Diálogo horizontal entre conhecimento cien- } \\
\text { tífico e conhecimento popular }\end{array}$ & \multirow{2}{*}{$\begin{array}{l}\text { O agir crítico em nutrição na APS pressupõe } \\
\text { participação, vínculo e construção } \\
\text { compartilhada }\end{array}$} & \multirow[t]{5}{*}{$\begin{array}{l}\text { O agir crítico em nutrição na APS é construído } \\
\text { de forma compartilhada e participativa }\end{array}$} \\
\hline $\begin{array}{l}\text { Construção de vínculos interpessoais, afetos } \\
\text { e amizade }\end{array}$ & & \\
\hline Construção compartilhada & $\begin{array}{l}\text { O agir crítico em nutrição na APS pressupõe } \\
\text { interdisciplinaridade }\end{array}$ & \\
\hline Ênfase em grupos sociais e comunitários & \multirow[t]{2}{*}{$\begin{array}{l}\text { O agir crítico em nutrição na APS requer edu- } \\
\text { cação em grupos comunitários }\end{array}$} & \\
\hline $\begin{array}{l}\text { Valorização do trabalho com os movimentos } \\
\text { e as redes de apoio social }\end{array}$ & & \\
\hline $\begin{array}{l}\text { Enfrentamento e luta contra o capitalismo e } \\
\text { seus valores, com alternativas de produção } \\
\text { sustentáveis e tecnologias leves de relações } \\
\text { humanas }\end{array}$ & \multirow[t]{2}{*}{$\begin{array}{l}\text { O agir crítico em nutrição na APS pressupõe } \\
\text { práxis }\end{array}$} & \multirow[t]{5}{*}{$\begin{array}{l}\text { O agir crítico em nutrição na APS é construído } \\
\text { em meio ao conflito e ao enfrentamento do } \\
\text { capitalismo }\end{array}$} \\
\hline Ação emancipatória & & \\
\hline $\begin{array}{l}\text { Reconhecimento e problematização dos con- } \\
\text { flitos entre os sujeitos }\end{array}$ & \multirow{3}{*}{$\begin{array}{l}\text { O agir crítico em nutrição é construído em } \\
\text { meio ao conflito e ao enfrentamento do ca- } \\
\text { pitalismo }\end{array}$} & \\
\hline $\begin{array}{l}\text { Enfrentamento e luta contra o capitalismo e } \\
\text { seus valores }\end{array}$ & & \\
\hline $\begin{array}{l}\text { Resistência ao capitalismo com alternativas } \\
\text { de produção sustentáveis e tecnologias leves } \\
\text { de relações humanas }\end{array}$ & & \\
\hline $\begin{array}{l}\text { Valorização do saber popular e da experiência } \\
\text { tradicional na construção de tecnologias de } \\
\text { promoção da saúde e da SAN }\end{array}$ & $\begin{array}{l}\text { O agir crítico em nutrição supera o } \\
\text { assistencialismo e reorienta o fazer clássico } \\
\text { da nutrição nas ações de SAN }\end{array}$ & $\begin{array}{l}\text { A EP contribuiu para um agir crítico que } \\
\text { reorienta o fazer tradicional e reposiciona o } \\
\text { trabalho em nutrição na perspectiva da SAN } \\
\text { e do DHAAS }\end{array}$ \\
\hline
\end{tabular}

Fonte: elaborado pelo autor.

O conjunto desses elementos está explicitado e problematizado no texto de tese do qual se originou este artigo, presente em Cruz (2015). Considerando os limites de tamanho da seção à que se destinou o presente manuscrito, assim como a necessidade de objetividade, optou-se por enfatizar aqueles elementos desvelados pela síntese da terceira e última rodada de análise. Nas próximas páginas, efetuar-se-á uma breve abordagem sobre cada um desses eixos.

\section{O agir crítico em nutrição na Atenção Primária à Saúde requer o engajamento e o compromisso com a realidade social}

Todo agir em nutrição é, evidentemente, envolto pela realidade social - seja no hospital, na clínica, no mundo esportivo, nas unidades de produção de refeições, nas indústrias e nos laboratórios, nas instituições acadêmicas, entre outros cenários.

O que determina a escolha do alimento se não for a realidade em que ele está inserido? O que vai determinar a minha conduta com a alimentação, com a nutrição, se não for a minha própria realidade? Como eu consigo fazer um agir crítico em nutrição se não for assim. [Entrevistada 1]. 
No entanto, na compreensão dos entrevistados, nem todo agir em nutrição se deixa encharcar pela realidade social circundante, conforme a acepção trazida por Freire (1996) nessa citação:

O compromisso, próprio da existência humana, só existe no engajamento com a realidade, de cujas 'águas' os homens verdadeiramente comprometidos ficam 'molhados', ensopados. (FREIRE, 1996, p. 19).

Do "deixar-se encharcar" pela realidade social emerge um engajamento, cristalinamente demonstrado por compromisso social. De acordo com as considerações dos sujeitos da pesquisa, um aprendizado importante dos primeiros passos de sua experiência no PINAB foi a priorização de buscar conhecer, sentir, vivenciar e 'mergulhar' na realidade do território de atuação, antes mesmo de se decidir sobre o que se ia fazer.

Com o passar do tempo, fui me despindo de quaisquer conceitos pré-formados $e$ fui adentrando aquela comunidade de coração aberto. A partir dessas vivências proporcionadas pela extensão, fui me sensibilizando [...] de que precisávamos de uma escuta, um abraço, uma consulta e um aprendizado. E foi nessa imensa troca de conhecimentos e desprendimentos, entre todos, que foi possível haver mais articulação na construção dos saberes e na busca da promoção à saúde e da superação dos problemas sociais. [Entrevistada 2].

As falas denotam, pois, ser preciso deixar que o nutricionista, ou qualquer outro profissional no campo da nutrição na APS, se engaje nas 'águas' da realidade local, ao invés de chegar já dizendo o que será feito, quais grupos serão empreendidos, escolher ações clássicas da nutrição - grupo de pessoas convivendo com obesidade, diabetes e hipertensão - ou, tão somente, reduzir sua dedicação a prescrever dietas e a aconselhar dietoterapias. Nos primeiros passos dos entrevistados em suas experiências, primeiramente, procedeu-se com o conhecer do território e das instituições que existiam lá. Em suas percepções, esse não é um trabalho simples, porque exige que se conheça o território e se dê abertura para o que ele vai demandar, inclusive extrapolar a atenção, e olhar para demandas e necessidades fora do campo clássico da alimentação e da nutrição. Tal imersão não flui naturalmente. Necessita, sobretudo, da decisão por se empreender um diálogo entre o saber acadêmico e o saber popular, tendo como ponto de partida as necessidades e os interesses locais.

Um agir crítico em Nutrição na APS implica buscar espaços e oportunidades sistemáticas de conviver com o território e seus grupos sociais. Como afirma Boog (2010, p. 1015), "[...] programas educativos que são pautados na realidade proporcionam oportunidades para identificar barreiras relativas à qualidade de vida, à emancipação e ao controle sobre a vida e o trabalho". Conforme presente nos vários depoimentos, é importante conversar com as pessoas, tendo um espaço permanente de encontro com elas. Não basta trazer a pessoa da comunidade para os processos educacionais de nutrição e tratá-la como um membro passivo do processo; é preciso tratá-la como membro de uma comunidade, como gente que tem um dia a dia, um espaço próprio, cheio de subjetividades e envolto por determinantes sociais. 
Lá na comunidade, eu podia respirar, encher meus pulmões de vida e voltar para aquela sala de aula com um novo ol har, um novo oxigênio que me mantinha viva até o próximo encontro com elas. [...] Foi com aquelas pessoas que eu aprendi o verdadeiro sentido não só de ser nutricionista, mas também de ser gente! Gente que se importa. Gente que sofre. Gente que respeita. Gente que aprende com o outro e assume a sua pequenez em uma das grandes disciplinas: viver! [Entrevistada 3].

Pretende-se, portanto, que essas pessoas tragam suas ideias, suas críticas, suas iniciativas e sua criatividade. Tais atitudes permitem a construção processual de um relacionamento marcado pelo vínculo, onde a formação é "[...] processo em construção, unindo conhecimento teórico e prática como exercício da profissão, [...] transformar vivências em caminhos de experiência, num esforço de respeito à autonomia e à identidade dos educandos" (SCHNEIDER; NEVES, 2014, p. 194).

\section{O agir crítico em nutrição na Atenção Primária à Saúde é construído de forma compartilhada e participativa}

Conforme exposto anteriormente, a partir dessa experiência, os entrevistados relatam que foram aprendendo que um agir crítico em nutrição requer ter um espaço permanente de encontro com as pessoas protagonistas do território de atuação na APS. E isso vai permitindo não apenas a construção de um compromisso profundo com a realidade social, mas também vai ensejando uma construção participativa dos processos educativos e das ações sociais.

Um educador popular nunca o será de fato se ele não conseguir sentir a comunidade, sentir-se um, para então poder lutar junto. Nesta tarde, fiz parte daquela comunidade. Senti-me naquela comunidade. Ela me transformou. [Entrevistada 4].

$\mathrm{Na}$ acepção dos sujeitos de pesquisa, foi importante para o PINAB criar grupos com agendas sistemáticas, dedicados prioritariamente ao cultivo de encontros com as pessoas do território para conversas sobre o cotidiano e as histórias de vida e de luta. Assim, conhecendoas profundamente e criando um contexto relacional favorável à construção compartilhada.

Durante as atividades coletivas, teve-se a intencionalidade de permiti-los [o grupo de idosos] perceber que não estávamos ali para um monólogo, onde um fala e o outro apenas ouve, mas, sim, que estavam em uma oportunidade de serem ouvidos, de exporem seu ponto de vista, suas experiências ou o que eles entendem por determinado assunto; [...] contrapondo a imagem tradicional de palestras, às quais eles estão habituados, onde só o palestrante tem o poder do discurso e, consequentemente, são considerados como 'donos do saber' e o outro, dono do assimilar [...]. É interessante ressaltar que os questionamentos levantados durante os encontros se deram a partir da fala de algum participante, por dinâmicas ou, até mesmo, por questionamentos elaborados pelos facilitadores, provocando o grupo a expor sua opinião sobre a reflexão surgida, gerando as discussões sobre a problematização em debate. [Entrevistada 4].

Conforme relatado pelos entrevistados, todas as pessoas que fazem parte dos trabalhos nesse campo têm que se empoderar das dimensões políticas e dos direcionamentos de cada 
atuação. No campo das práticas de EAN, isso pressupõe que é preciso compartilhar com as pessoas da comunidade, por exemplo, o poder de decisão sobre os temas a serem discutidos nos espaços de encontro e as atividades educativas. Como afirmam Schneider e Neves (2014), as ações de EAN podem constituir oportunidades únicas de se desenrolar um processo mútuo de convivência para a aprendizagem, o qual se afina mais adequadamente a um horizonte emancipatório para o cuidado em saúde e o trabalho em saúde.

Em comparação às conversas teóricas, as vivências práticas no/do tema deixam a desejar. Perde-se a oportunidade de entrar na rede, de compartilhar outro/seus modos de estar no mundo, de interagir com outras linguagens, de trilhar rumos para a participação ativa e cidadã. Articular saberes e apreender a realidade ficam desprestigiados, reforçando a famosa dicotomia teoria/prática (SCHNEIDER; NEVES, 2014, p. 189).

Mas, de acordo com as falas dos sujeitos da pesquisa, tal dimensão extrapola esse compartilhar de poderes na decisão de temas. Exige uma abordagem participativa de tais temas, de modo que seja valorizado o saber de experiência de cada sujeito inserido nas atividades, que devem ter como ponto de partida o concreto vivido em suas realidades, na dinâmica dos grupos sociais locais, conforme demonstrado nestes discursos:

No trabalho com os adolescentes da Escola, ouvir, dialogar, mostrar que a bagagem de conhecimento que trazem é importante, respeitar sua visão de mundo e apresentar novos caminhos em vista da promoção da saúde e de uma alimentação saudável favoreceu o fortalecimento do vínculo entre os extensionistas e os estudantes [...]. Quando eram colocadas nas discussões as perguntas condutoras com as respostas dos adolescentes, iam surgindo mais questionamentos e reflexões que potencializavam suas falas. [Entrevistada 1].

Um elemento fundante para essa construção compartilhada é, necessariamente, o reconhecimento autêntico da capacidade de ser mais (FREIRE, 1996) de cada indivíduo na comunidade. É essencial a confiança em dispor a esses sujeitos e seus grupos sociais o íntimo de cada atividade educativa, de modo que possam opinar, interferir e participar.

Pra você pensar o agir crítico em nutrição, você precisa da criação do vínculo, e para você criar um vínculo, precisamos reconhecer aquelas pessoas como parceiros. Você reconhecendo o outro como sujeito de igual para igual [...]. Na experiência da horta, [...] existem dois meninos lá que já são maiores que os outros que participam, e conversamos mais com eles, porque eles mobilizam os menores. E notamos que não é preciso estarmos lá para eles cuidarem [...]. [Entrevistada 5].

Nesse sentido, o papel do agir crítico em nutrição na APS é também o de promover a autogestão dos processos sociais e educativos empreendidos no território. Todo processo que se desenvolve tem que estar preocupado com a sustentabilidade, independentemente de quais pessoas estão envolvidas. Nesse sentido, o trabalho coletivo, solidário e em equipe, revela-se fundamental. Cabe, então, ao nutricionista abrir-se às ricas possibilidades presentes do diálogo interdisciplinar. 


\title{
O agir crítico em nutrição na Atenção Primária à Saúde é construído em meio ao conflito e ao enfrentamento do capitalismo
}

A construção de um agir crítico em nutrição na APS requer dos sujeitos das práticas sociais e profissionais a compreensão de que a alimentação e a nutrição são dimensões do viver que convivem com intensas dinâmicas complexas e conflituosas no cotidiano de cada pessoa e de seus grupos sociais territorializados. Abordar os processos de promoção integral da saúde no campo alimentar e nutricional exige, portanto, enfrentar a condição de conflito inerente a esses fenômenos. Como nos diz a Entrevistada 1, "Não tem transformação sem conflito".

Ora, em sendo o fenômeno da nutrição algo intimamente ligado à alimentação como ação cultural, tanto a alimentação quanto a nutrição são elementos do cotidiano das pessoas que estão sujeitas às mudanças próprias da realidade social, aos jogos de interesses nas relações humanas, às questões econômicas e políticas da vida em comunidade, entre outros fatores.

\begin{abstract}
A nutrição é algo que, desde os primórdios, o homem necessita [...]. Ao longo da evolução da sociedade, as formas de buscar essa Nutrição mudaram bastante, e essa ação também passou a incorporar outras relações de forma de produção, formas de obtenção de alimentos. [...] Oobjetivo da alimentação antigamente era uma questão de sobrevivência, e na sociedade atual engloba muitos outros fatores. Então, [...] a alimentação permeia todas as ações do ser humano, continua sendo ainda uma necessidade vital, mas, junto a ela, vem as relações de trabalho, de cultura, como cada indivíduo consegue seu alimento e pra que ele consegue aquele alimento: só para sobrevivência, qualidade de vida, para outros fins, para o comércio, para subsistência. Eo agir crítico em nutrição tem a responsabilidade de entender os mecanismos que acompanham o ato simplório de se nutrir do ser humano. [...] Esse agir crítico vem para pensar sobre essa ação simples do nutrir. [Entrevistado 7].
\end{abstract}

No que se refere ao conflito, também foi pontuado pelas pessoas entrevistadas que outra dimensão do mesmo no agir crítico em nutrição está em compreender os diferentes projetos sociais e políticos presentes na realidade de cada território da APS. No contexto da ação na comunidade e de seus grupos sociais, foi importante na experiência do PINAB considerar que há uma diversidade significativa de interesses e de compreensões acerca da realidade comunitária, o que se verifica também em diferentes abordagens e posturas - de diferentes atores - quanto ao enfrentamento dos problemas sociais locais. No PINAB, isso foi observado no decorrer dos treze anos de sua vivência com a comunidade, mas se expressou, sobretudo, quando, no início do Programa, sua equipe dedicou tempo a procurar, a conversar e a conhecer os diferentes grupos sociais comunitários.

Um terceiro elemento atinente à dimensão do conflito foi expresso pelos entrevistados quando abordaram a dinâmica tensa que por vezes se estabelece entre os protagonistas da comunidade e os trabalhadores da equipe de APS. De acordo com os entrevistados, nesses momentos, na perspectiva do agir crítico em nutrição, foi preciso avaliar o contexto e se posicionar. Isso não implica se posicionar sempre a favor dos grupos da comunidade e contra os trabalhadores do serviço de saúde, pois a convivência conflituosa não significa, necessariamente, que o serviço irá oprimir as pessoas da comunidade. Ocorre, em muitas vezes, o contrário: agentes comunitários extremamente autoritários em ação para ganhos 
políticos outros que não aqueles da coletividade e da qualificação dos espaços e dos serviços públicos. Para as pessoas entrevistadas, nesse momento, a EP ensinou que os conflitos entre os grupos sociais comunitários e os membros do serviço devem ser respeitados, mas também, recomenda-se exercitar uma leitura crítica sobre tais conflitos, a primorando o olhar sobre aliados e antagonistas de um projeto político e social para a promoção da saúde, da cidadania e da qualidade de vida na comunidade.

Isso é o que faz um agir em nutrição que busca ser crítico. Não cabe, assim, neutralidade. Mas o rompimento com a neutralidade não pode se dar de forma simplista e apressada; precisa ser feito com estudo, análise de contexto e decisão coletiva. Em uma abordagem permeada pela EP, cabe problematizar as atitudes, as posturas e as falas dos sujeitos de cada grupo social da comunidade, analisando coletivamente o modo de intervir de cada um nos processos educacionais e avaliando sua interferência no andamento das ações. Na experiência do PINAB, os entrevistados afirmam que isso se dava colocando essas situações em pauta nas próprias reuniões do Programa, abrindo-se a conversa e dialogando, através da disposição em sentar e conversar com os sujeitos do território e seus grupos sociais, a fim de escutar sua fala e compreender suas posições para respeitá-las, mesmo sem concordar com elas. Os conflitos exigem dos educadores populares uma postura de escuta, respeito e diálogo para que, mesmo em um momento de tensão, compreendam a fala do outro, seus sentidos e percepções.

Ainda na acepção dos entrevistados, para o agir no trabalho em nutrição ser crítico, uma quarta dimensão do conflito está em compreender a dinâmica do capitalismo e suas consequências no concreto vivido no território da APS. Na visão dos entrevistados, o trabalhador em saúde deve se perceber inserido no Brasil, convivendo em um contexto capitalista, neoliberal e bastante desmobilizador das pessoas, em que a ênfase de ação social está em estimular as pessoas a resolverem os próprios problemas.

\begin{abstract}
Se o capitalismo é o sistema vigente da nossa sociedade, o agir crítico em nutrição precisa necessariamente entender esse cenário, e o conflito é determinado pela cadência do capitalismo. Para conseguir se estruturar, torna-se necessário entender e contextualizar a situação da sociedade hoje em dia. Então, se a situação da sociedade hoje em dia é pelo capitalismo, pela luta de classes, pela dicotomia do opressor versus oprimido, é necessário, sim, compreender os mecanismos de como funciona o sistema capitalista. [...] se o objetivo desse agir é abarcar esse capitalismo para transformá-lo, deve-se então compreendê-lo em longo prazo, em médio prazo. [Entrevistado 7].
\end{abstract}

Os entrevistados ressaltam que não se pode perder de vista, no cotidiano da ação em nutrição na APS, que a tônica da organização econômica atual está no capitalismo, em que o estímulo dado a cada um é de ganhar mais dinheiro e ser bem-sucedido, independentemente das demais pessoas e dos grupos sociais. As pessoas interessam-se muito pouco em dedicarse a projetos sociais e políticos ampliados, participativos, solidários e humanizadores. $\mathrm{O}$ nutricionista - ou profissional atuante em alimentação e nutrição - precisa estar atento a esse contexto. Na experiência do PINAB, a EP fundamentou uma vivência em que se valorizou essa dimensão, para provocar um novo foco no olhar dos estudantes de Nutrição. 
O PINAB, no contexto geral, já faz isso a partir do momento que um estudante vai para a comunidade sem lucro nenhum, é voluntário, e que vai tentar promover saúde para aquelas pessoas, com aquelas pessoas; vai atrás da troca, de escutar, de aprender. Porque, geralmente, o estudante vai com uma ideia de muito mais aprender, do que ensinar alguma coisa lá. Então, acho que isso já foge da ideia do capitalismo. Tem muito mais forte a ideia do social [...]; como eles podem integrar a comunidade, como ali é uma área de cultura, que pode germinar e gerar uma transformação. Que não seja da realidade num todo, mas pelo menos naquele local [...] [Entrevistada 2].

Pois, foi a leitura da vida quem me ensinou que eu não estava sentada naquela cadeira quente e desconfortável da universidade para ser um homem robô, programado para falar e escrever o que havia lido em artigos científicos e literatura conceituada, esquecendo-me que sou além de intelecto, sou também emoção e valores. Foi a leitura da vida que me ensinou que, enquanto o que aprendo no saber científico me é importante, o é também importante aquela Joana da periferia de minha cidade, en enuanto meu saber científico é importante, o saber da Joana aprendido na casa, na rua, na repartição pública, no choro, na fome, no não recebido, também me é essencial e essencial a ela. [Entrevistada 4].

Compreender os conflitos sociais e humanos trazidos pelo sistema capitalista e as outras contradições sociais e econômicas propicia, inclusive, mais abertura para o diálogo e a construção compartilhada entre as pessoas, como mostram estes discursos:

Nas brechas do capitalismo, a partir das limitações do sistema, da visão crítica da sociedade que anseia por uma mudança desse sistema, a gente pode começar a trabalhar. Para entender, precisamos saber quais são os pontos fracos do sistema, porque se é o sistema que você deseja mudar, tem que entender os pontos fracos. [Entrevistado 7].

Os conceitos de SAN e de DHAAS trazem, como imagem-objetivo, muito mais do que o fim da fome e da miséria. Objetivam a emancipação social, humana e política das pessoas, a partir de onde poderão realizar sua soberania alimentar. Para tanto, um elemento fundamental é sua participação ativa, altiva e crítica na condução de suas vidas, particularmente, na produção de sentidos que as estimulem cotidianamente a buscarem com suas próprias forças - caminhos para superar os problemas. Assim, a análise das falas dos entrevistados permite-nos compreender que o agir crítico em nutrição na APS pressupõe incentivar, com insistência e persistência, o papel protagônico das pessoas e dos grupos sociais na construção de bases sustentáveis para conduzirem suas vidas com dignidade.

Temos várias experiências no PINAB que comprovam que o agir crítico em nutrição transpassa esse caráter assistencialista, [...] fazendo com que as pessoas que estão inseridas nesse programa reflitam o que ele é e o que ele faz, e o que elas podem fazer para se sustentar além dele também. A construção da horta em si não passa por um processo assistencial, ela já passa esse caráter além do assistencial das pessoas que estão produzindo, estão se utilizando daquele produto que elas colocaram para plantar e colher. [Entrevistada 6]. 
No contexto de programas sociais de combate à miséria e da promoção da SAN, tal postura exige que o profissional valorize as estratégias de transferência condicionada de renda ou a distribuição de alimentos, mas apenas como estratégia pontual e emergencial, necessariamente articulada a investimentos sociais e políticos consideráveis para ações, programas e projetos que ajam estruturalmente nas causas da insegurança alimentar. Conforme apontam estudos como o de Santos et al. (2019), as últimas décadas testemunharam avanços nas ações governamentais estruturantes com ênfase nas raízes de alguns problemas. Como indicam Jaime et al. (2018), particularmente entre 2003 e 2016, destacaram-se investimentos e ações apoiadas como iniciativas sustentáveis e saudáveis de produção de alimentos, visando à soberania alimentar. Conforme assevera Sátyro et al. (2019), esse processo ocorreu no contexto de políticas públicas voltadas à promoção de espaços e equipamentos sociais, de programas educativos e de estratégias de proteção social, as quais foram marcantes na América Latina nas experiências de alguns países nas últimas duas décadas.

Contudo, percebem-se também algumas contradições nesse processo de avanço institucional, sobretudo no que tange ao tímido incentivo à participação popular nas ações de SAN, na pouca articulação intersetorial visando qualificar as ações nesse campo (especialmente entre educação, saúde, agricultura e assistência social) e na escassa ênfase à dimensão educacional das ações de SAN, que se restringem, muitas vezes, a uma mera fiscalização de condicionalidades. Como analisam Castro et al. (2009, p. 336-337), políticas públicas inclusivas, em meio a um contexto capitalista de redução do Estado, "[...] se mantêm na esfera pública [de modo] seletivo, focalizado e atua principalmente junto aos mais pobres dentre os pobres, na forma de políticas compensatórias". Enquanto se reconhece o robusto avanço institucional em políticas governamentais e em marcos legais na direção da inclusão social, Castro et al. (2009) alertam sobre a incompatibilidade entre os ajustes estruturais da economia e os investimentos sociais do Estado, com políticas sociais adquirindo perfil despolitizado e na linha da filantropia.

Tais considerações são fundamentais para o agir de modo crítico no trabalho em nutrição. Além dos fatores citados, especialmente na APS, o profissional deve atentar para percepções e ações distorcidas dos programas sociais de SAN, demarcadas por um uso eleitoreiro e utilitarista dessa estratégia, valorizando-se, por demais, somente a transferência condicionada de renda, como exposto em pesquisa de Castro et al. (2009). Como pontua Fleury (2018), há ainda que se ponderar o fato de que, a partir de 2016, a ênfase da ação governamental passa a ser caracterizada pela austeridade, concretizada pelos cortes do investimento público em políticas de proteção social e de apoio ao desenvolvimento sustentável. Isso não apenas ameaça significativamente o desenvolvimento de uma dimensão estruturante para as políticas de SAN e de DHASS, mas, inclusive, coloca em cheque a própria existência das mesmas na esfera pública nacional, haja vista a extinção do Conselho Nacional de Segurança Alimentar e Nutricional (CONSEA), como um dos primeiros atos da atual gestão do Governo Federal.

Nessa direção, importa ao agir crítico em nutrição na APS exercitar estratégias locais para possibilitar o desenvolvimento de uma abordagem estruturante, sustentável e participativa dos programas de SAN, que se afaste de ações puramente assistencialistas e clientelistas. 


\section{As contribuições da EP para um agir crítico na APS que reorienta o fazer tradicional e reposiciona o trabalho em nutrição na perspectiva da SAN e do DHAAS}

Na visão dos sujeitos entrevistados, a experiência demonstrou que, por meio da $E P$, podem-se delinear estratégias participativas e críticas de formação estudantil, de construção da promoção da saúde e de fomento à SAN com os grupos sociais comunitários, o que oportunizou o desenvolvimento das atividades com parceria, proatividade e comprometimento. A EP tem princípios, intencionalidades e abordagens capazes de trazer elementos para a superação da distância entre o debate crítico em torno da Nutrição (principalmente no campo da SAN) e suas realizações no campo prático, particularmente as educacionais.

Nessa experiência, a perspectiva da Educação Popular provou ter um papel singular, à
medida em que se conseguiu provocar uma discussão sobre SAN conducente à tomada
de atitudes e à conscientização. Pode-se pensar em outra direção para o trabalho do
Agente Comunitário de Saúde, no âmbito do Programa Saúde da Família, que não se
restrinja à prescrição de condutas e à verificação do estado nutricional da população
infantil, mas que ponha a realidade social em diálogo com as condições de saúde e de
SAN da comunidade, rumo à promoção de uma boa qualidade de vida. [Entrevistada 4].

Nesses termos, pela EP, os entrevistados denotaram a constituição de um agir em nutrição que perpassa uma abordagem da Ciência da Nutrição capaz de compreender a si mesma como uma ciência multifacetada e determinada por diferentes elementos, tais como o social, o econômico, o político, o cultural, o espiritual, o mental, entre outros. Uma ciência cujo ponto de partida é a realidade, suas contradições e seu movimento, compreendendo o fenômeno nutricional com sua natureza biológica e fisiológica, mas, centralmente, indissociado de um entendimento ampliado da alimentação, como uma prática social, cultural e plena de sentidos nas vidas das pessoas e das coletividades. Tal aporte teórico exige dessa ciência elementos práticos condizentes com esses horizontes conceituais.

Como apontado por Cruz (2015), experiências de EAN orientadas por perspectivas educacionais críticas, como a EP, vêm sendo desenvolvidas há muitas décadas, ampliandose, de modo especial, desde os anos de 1970, especialmente em contextos de exclusão social e no âmbito de comunidades e territórios com ações sanitárias centradas em famílias. A Rede Ideias na Mesa, vinculada à Universidade de Brasília (UNB), constituiu um espaço virtual de articulação e de compartilhamento de experiências em EAN de todo o país. No ano de 2016 registraram-se em seu portal eletrônico 9.365 usuários com 226 experiências intersetoriais cadastradas, 39 boletins e informativos publicados, três cursos a distância e 8 revistas publicadas (REVISTA IDEIAS NA MESA, 2016). Souza et al. (2019), analisando uma experiência no contexto de hortas urbanas comunitárias, destacam a contribuição desse fazer pedagógico para o aprimoramento dos vínculos da vida comunitária e na continuidade de iniciativas para a participação ativa nos movimentos sociais, proporcionando um caráter socializador e dinâmico de tais espaços urbanos produtivos. 
Os processos educativos em alimentação e nutrição referenciados pelo escopo teóricometodológico da EP traduzem-se centralmente em processos de construção compartilhada de ações profissionais e de trabalhos sociais, tendo como ponto de partida a realidade concreta e o diálogo autêntico, respeitoso e propositivo com seus sujeitos e grupos (CRUZ; MELO NETO, 2014). Em seu delineamento, tais experiências configuram procedimentos e abordagens que valorizam a cultura popular e o fazer interprofissional, indo, portanto, na contramão de um agir pautado pelo seguimento obediente, acrítico e passivo de protocolos de ação profissional, em especial aqueles pouco contextualizados com as realidades de cada território de ação na APS.

\section{Considerações Finais}

Com este manuscrito espera-se contribuir para manter aceso o debate sobre os esforços que muitos autores e muitas experiências sociais já vêm mantendo para promover possibilidades para o agir em nutrição na APS, particularmente apresentando como contribuição a possibilidade de haver uma interlocução com a EP. Sendo assim, pondera-se que - em que pese o fato de muitos autores e diversas obras terem avançado no sentido de delinear possibilidades educativas que ajudem a concretizar no âmbito prático e profissional os objetivos e os princípios de SAN e de DHAAS - é necessário, no atual contexto de exclusão social, dedicar mais estudos e reflexões sobre processos de trabalho em nutrição e em EAN na APS.

Considerando as percepções de participantes de uma experiência, indicamos, ao final deste artigo, que o agir crítico em nutrição na APS possui dimensões significativas, quais sejam: (1) engajamento e compromisso com a realidade social; (2) construção de forma compartilhada e participativa; (3) construção em meio ao conflito e ao enfrentamento do capitalismo; e, (4) reorientação do fazer tradicional em nutrição com consequente reposicionamento do trabalho em nutrição para a perspectiva da SAN e do DHAAS.

Apontou-se que, pela metodologia da educação popular (EP), o trabalho na Atenção Primária à Saúde (APS) pode construir práticas de Educação Alimentar e Nutricional (EAN) orientadas pelo diálogo acerca das estratégias para posicionar alimentação e nutrição de maneira coerente com a compreensão da saúde como qualidade de vida e bem viver. Na perspectiva de um agir crítico, o trabalho em nutrição pode desvelar estratégias locais e processos de articulação, de luta e de mobilização para a aproximação da conquista da soberania alimentar e da emancipação humana. Pela EP, deflagra-se um agir em nutrição na APS pautado pelo desvelamento crítico da realidade alimentar e nutricional de cada território. Esse agir tem como horizonte o apoio a formulação de políticas públicas estruturantes, a construção de ações profissionais emancipadoras e socialmente referenciadas, bem como o delineamento de espaços, de práticas sociais e de experiências comunitárias promotoras de SAN. Com tais pressupostos e características, esse agir é capaz de subsidiar o enfrentamento sistemático dos processos de insegurança alimentar e de exclusão social nos territórios da APS. 


\section{Referências}

ACIOLI, S.; AZEVEDO, D. C. V.; PASCOAL, R.; FERREIRA, V. S.; SILVA, A. B. P. Reflexões sobre a construção compartilhada do conhecimento em saúde na localidade do Alto Simão/Vila Isabel - RJ. Interagir: pensando a extensão, Rio de Janeiro, n. 2, p. 17-22, ago./dez. 2002. Disponível em: http:// tinyurl.com.br/69a. Acesso em: 20 ago. 2020.

BOOG, M. C. F. Programa de educação nutricional em escola de ensino fundamental de zona rural. Revista de Nutrição, Campinas, v. 23, n. 6, p. 1005-1017, nov./dez. 2010. DOI: http://doi.org/bgfnvr.

BRASIL. Ministério da Saúde. Conselho Nacional de Saúde. Resolução n. 466, de 12 de dezembro de 2012: aprova diretrizes e normas regulamentadoras de pesquisas envolvendo seres humanos. Brasília: Ministério da Saúde, 2012.

BRASIL. Ministério da Saúde. Secretaria de Atenção à Saúde. Guia alimentar para a população brasileira. 2. ed. Brasília: Ministério da Saúde, 2014. Disponível em: http://tinyurl.com.br/69b. Acesso em: 20 ago. 2020.

BRUTSCHER, V. J. Gestão, direito e participação no SUS. Revista Brasileira de Ciências da Saúde, João Pessoa, v. 16, n. 3, p. 401-410, 2012. Disponível em: http://tinyurl.com.br/69c. Acesso em: 20 ago. 2020.

CASTRO, H. C. O.; WALTER, M. I. M. T.; SANTANA, C. M. B.; STEPHANOU, M. C. Percepções sobre o programa bolsa família na sociedade brasileira. Opinião Pública, Campinas, v. 15, n. 2, p. 333-355, 2009. Disponível em: http://tinyurl.com.br/77t. Acesso em: 20 ago. 2020.

CASTRO, I. R. R.; CASTRO, L. M. C.; GUGELMIN, S. A. Ações educativas, programas e políticas envolvidos nas mudanças alimentares. In: DIEZ-GARCIA, R. W.; CERVATO-MANCUSO, A. M. (coord.). Mudanças alimentares e educação nutricional. Rio de Janeiro: Guanabara Koogan, 2011. p. 18-34.

CONTRERAS, J.; GRACIA, M. Alimentação, sociedade e cultura. Rio de Janeiro: Fiocruz, 2011.

CRUZ, P. J. S. C. Agir crítico em nutrição: uma construção pela educação popular. 2015. 513 f. Tese (Doutorado em Educação) - Centro de Educação, Universidade Federal da Paraíba, João Pessoa, 2015. Disponível em: http://tinyurl.com.br/77v. Acesso em: 20 ago. 2020.

CRUZ, P. J. S. C.; MELO NETO, J. F. Educação popular e nutrição social: considerações teóricas sobre um diálogo possível. Interface, Botucatu, v. 18, n. 2, p. 1365-1376, 2014. DOI: http://doi.org/d6dc.

FLEURY, S. Capitalismo, democracia, cidadania: contradições e insurgências. Saúde Debate, Rio de Janeiro, v. 42, n. 3, p. 108-124, 2018. DOI: http://doi.org/d6dd.

FREIRE, P. Pedagogia da autonomia: saberes necessários à prática educativa. Rio de Janeiro: Paz e Terra, 1996.

GIOVANELLA, L.; MENDONÇA, M. H. M. Atenção primária à saúde. In: GIOVANELLA, L. et al. (org.). Políticas e sistema de saúde no Brasil. Rio de Janeiro: Fiocruz, 2008. p. 575-625.

GUERRA, L. D. S.; CERVATO-MANCUSO, A. M.; BEZERRA, A. C. D. Alimentação: um direito humano em disputa: focos temáticos para compreensão e atuação em segurança alimentar e nutricional. Ciência e Saúde Coletiva, Rio de Janeiro, v. 24, n. 9, p. 3369-3394, 2019. DOl: http://doi.org/d6df.

JACOB, M. C. M.; CHAVES, V. M. Falhas do sistema alimentar brasileiro: contribuições da geografia literária para o fortalecimento da democracia alimentar. Physis, Rio de Janeiro, v. 29, n. 1, e290106, 2019. DOI: http://doi.org/d6dg.

JAIME, P. C.; DELMUÈ, D. C. C.; CAMPELLO, T.; SILVA, D. O.; SANTOS, L. M. P. Um olhar sobre a agenda de alimentação e nutrição nos trinta anos do sistema único de saúde. Ciência e Saúde Coletiva, Rio de Janeiro, v. 23, n. 6, p. 1829-1836, 2018. DOI: http://doi.org/d6dh. 
JAIME, P. C.; SILVA, A. C. F.; LIMA, A. M. C.; BORTOLINI, G. A. Ações de alimentação e nutrição na atenção básica: a experiência de organização no governo brasileiro. Revista de Nutrição, Campinas, v. 24, n. 6, p. 809-824, 2011. DOI: http://doi.org/d6dj.

MARQUES, A. P. P. Reestruturação produtiva e recomposições do trabalho e emprego: um périplo pelas "novas" formas de desigualdade social. Ciência e Saúde Coletiva, Rio de Janeiro, v. 18, n. 6, p. 1545-1554, 2013. DOI: http://doi.org/d6dk.

MELO NETO, J. F. Dialética: uma visão marxista. In: MELO NETO, J. F.; CEZARINO, H.; CARNEIRO, G. M. (org.). Dialética. João Pessoa: UFPB, 2002. p. 83-121.

MINAYO, M. C. S. O desafio do conhecimento: pesquisa qualitativa em saúde. 11. ed. São Paulo: Hucitec, 2008.

PRADO, S. D.; GUGELMIN, S. A.; MATTOS, R. A.; SILVA, J. K.; OLIVARES, P. S. G. A pesquisa sobre segurança alimentar e nutricional no Brasil de 2000 a 2005: tendências e desafios. Ciência e Saúde Coletiva, Rio de Janeiro, v. 15, n. 1, p. 7-18, 2010. DOI: http://doi.org/dq3zkj.

REVISTA IDEIAS NA MESA. Brasília: Universidade de Brasília, n. 8, 2016.

RIBEIRO, P. T. A questão social na história recente: implicações para a política de saúde no Brasil. Physis, Rio de Janeiro, v. 20, n. 1, p. 19-31, 2010. DOI: http://doi.org/fgqgh8.

SANTOS, L. A. S. Educação alimentar e nutricional no contexto da promoção de práticas alimentares saudáveis. Revista de Nutrição, Campinas, v. 18, n. 5, p. 681-692, 2005. DOI: http://doi.org/bjrgm7.

SANTOS, L. A. S. O fazer educação alimentar e nutricional: algumas contribuições para reflexão. Ciência e Saúde Coletiva, Rio de Janeiro, v. 17, n. 2, p. 453-462, 2012. DOI: http://doi.org/d6dm.

SANTOS, M. C. S.; DELATORRE, L. R.; CECCATO, M. G. B.; BONOLO, P. F. Programa bolsa família e indicadores educacionais em crianças, adolescentes e escolas no Brasil: revisão sistemática. Ciência e Saúde Coletiva, Rio de Janeiro, v. 24, n. 6, p. 2233-2247, 2019. DOI: http://doi.org/d6dn.

SÁTYRO, N. G.; FREITAS, R.; ZANETTI, D.; BARBOSA, P. M. R. Comparando políticas sociais em governos de esquerda. Caderno CRH, Salvador, v. 32, n. 85, p. 125-148, 2019. DOI: http://doi.org/ d6dp.

SCHNEIDER, O. M. F.; NEVES, A. S. Conversas sobre formarfazer a nutrição: as vivências e percursos da liga de segurança alimentar e nutricional. Interface, Botucatu, v. 18, n. 48, p. 187-196, 2014. DOI: http://doi.org/d6dq.

SOUZA, J. S.; CARDOSO, R. C. V.; PARAGUASSÚ, L. A. A.; SANTOS, S. F. The experience of community urban gardens: social organization and food security. Revista de Nutrição, Campinas, v. 32, e180291, 2019. DOI: http://doi.org/d6dr.

WELLER, W. Grupos de discussão na pesquisa com adolescentes e jovens: aportes teóricometodológicos e análise de uma experiência com o método. Educação e Pesquisa, São Paulo, v. 32, n. 2, p. 241-260, 2006. DOI: http://doi.org/dhhtx4.

WELLER, W.; SANTOS, G.; SILVEIRA, R. L. L.; ALVES, A. F.; KALSING, V. S. S. Karl Mannheim e o método documentário de interpretação: uma forma de análise das visões de mundo. Sociedade e Estado, Brasília, v. 17, n. 2, p. 375-396, 2002. DOI: http://doi.org/csmvvp. 